\title{
OPTIMIZATION OF SLIDING WEAR PARAMETERS FOR Mg/Grp COMPOSITES BY GREY RELATIONAL ANALYSIS
}

\author{
A. Dhinakar ${ }^{1}$, T. Panneer Selvam², S. Raghuraman ${ }^{3}$ \\ School of Mechanical Engineering, SASTRA University, Thanjavur - 613 401, \\ Tamilnadu, INDIA.
}

\begin{abstract}
:
Composite materials are generally made up of two constituents-matrix and reinforcement. The matrix material is stable and provides support to the reinforcement material. A variety of moulding methods can be used to prepare composites based on the type of application. The objective of manufacturing a new composite material is to improve the mechanical properties such as strength, stiffness, toughness and high temperature performance. The size of the reinforcement determines its potential of contributing its properties to the composite. As magnesium is being the one of the most abundant and lightest of all metals, it can be the best replacement for the material used in aerospace and automotive industry as composite material. Wear characteristic of magnesium is poor, but wear resistant is an important property for the industrial metals. As graphite is being soft and lubricant material, it is mixed in the proportion of $5 \%, 10 \%$, and $15 \%$ with magnesium, processed by powder metallurgy technique, then extruded and machined to conduct pin-on-disc test by Taguchi L9 orthogonal array design. Wear test is carried out on Standard C45 steel disc; wear loss and coefficient of friction are observed during the test. Grey Relational Analysis is used to optimize the wear reducing parameters and Analysis of Variance is performed to identify the significance of the parameters.
\end{abstract}

Keywords: Metal Matrix Composite, Magnesium, Graphite, Powder Metallurgy, Extrusion, Tribology, Sliding Wear, pin-on-disc method, Grey Relational Analysis, ANOVA.

\section{INTRODUCTION}

Metals and alloys are very useful and versatile materials and have been exploited almost fully. Further improvement can be achieved by combining them with reinforcements such as B, C, $\mathrm{Al}_{2} \mathrm{O}_{3}$ and $\mathrm{SiC}$ to produce metal matrix composites. In the sixties, Boron reinforced aluminium was developed and put to use in space shuttle by U.S.A. In the eighties and nineties, fibres such as silicon carbide and aluminium oxide, which are capable of withstanding very high temperatures, were used to reinforce metals at economical prices. The uses of Metal Matrix Composites (MMCs) have been increasing day by day ever since then.

In MMC reinforcements (or) fillers carry proportionally greater part of load than their volume fraction; fillers can impede plastic deformation of composite by reducing the mobility of dislocations. Depending on brittleness of matrix and the identity of the filler, surface and subsurface cracking can lead to delaminating fracture. An interface layer can be established by smearing of material of the matrix or matrix + filler in the interface, or counter body. Debonding of fillers from matrix promote wear. Reinforcement of metal by oxide fillers can enhance wear resistance during dry sliding wear resistance by reducing the tendency to adhesion. Composites containing weakly bonded fillers can suffer surface and sub-surface cracking due to loss of ductility, with a detrimental effect on wear resistance at high applied load. Loose Particle of hard fillers can be trapped at interface between the sliding partner, and lead to abrasive action 
on both the solid body and counter body. Small percentage of decrease in wear probably is cost effective. Wear is one of removal of materials from a surface, but wear system are such that with few exceptions the process of material removal have not been observed directly. This is usually quite slow in real system [1].

Usually MMCs possess superior wear resistance compared with unreinforced metals. A lot of research on the dry sliding wear behaviour of MMCs has been reported [2-7]. The degree of improvement of wear resistance of MMCs is strongly dependent on the kind of reinforcement as well as its volume fractions. However, particle reinforcement is most beneficial for improving the wear resistance of MMCs than whiskers and fibres [5]. Even though, the wear rate of composites as well as the matrix alloy increases abruptly above a critical load, due to massive surface damage and material transfer to the counter face [7]. Abrasion and adhesion were the dominant wear mechanisms with a transition to thermal softening only at the highest sliding speed [6]. Wear resistance of AZ91 magnesium alloy matrix composite improved substantially with increase in graphite particle content [3]. At low load, the wear mechanism is abrasive and oxidation wear; at high load, the wear mechanism changes to delaminating wear for all composites [4].

In case of magnesium matrix reinforced Silicon Carbide composites, the most effective factor on wear is volume fraction followed by reinforcement particle size and matrix particle size, wear loss decreases with increasing values of these factors while matrix particle size has contradictory effect [8]. Even in case of abrasive wear the wear resistance increases with size of reinforcement particle [9].

There are considerably less work done on magnesium and its alloy. Works related to Graphite reinforcements and Magnesium matrix composite, their interface bonding, damping and tensile properties where discussed and reported [10-13]. It is needed to evaluate the performance of these magnesium based MMCs with corresponding optimization of the treatment, in order to fully evaluate the advantages of this technology [2]. Grey relational analysis is a technique which is more convenient and economical to predict the effects of different influential combination of the parameters within the levels studied [14]. A grey relational analysis of the parameters obtained from Taguchi method can convert optimization of the multiple performance characteristics in to optimization of a single performance characteristic called the grey relational grade. As a result, optimization of complicated multiple performance characteristics can greatly be simplified through this approach [15]. ANOVA approach is used with this optimization technique will be able to provides systematic and effective methodology [16].

In present study graphite(Grp) powder mixed in proportion of 5\%, $10 \%$ and $15 \%$ with magnesium $(\mathrm{Mg})$, is processed by powder metallurgy technique and its wear characteristics is observed with the help of pin-on-disc configuration by using Taguchi L9 orthogonal array design. Wear test is carried out against a Standard C45 steel disc; wear loss and coefficient of friction are observed during the test. Grey Relational Analysis is used to optimize the parameters for minimum wear loss and maximum hardness.

\section{EXPERIMENTAL}

\subsection{Materials}

Composite specimen was prepared in the form of pin which is extruded from as sintered and compacted billet. Matrix material used for the composite was magnesium powder of size (>) 63 micron size and reinforcing material of graphite powder. With the help of an indigenous mixer chamber matrix and reinforcements were mixed in appropriate ratio. In this chamber, powders of 
magnesium and graphite were mounted in correct proportion by mass and $\mathrm{SiC}$ balls of varying diameters were also mounted to mix the powder thoroughly.

Further, cold pressing was done at 50 ton load and sintering was performed for one hour at a temperature of $300^{\circ} \mathrm{C}$. The die and punch used for compaction was designed and manufactured using high chromium and high carbon tool steel. In an UTM machine, hydraulic pressure on the powder loaded in die compacted in to a cylindrical shape set as green billet which was then sintered in electrical furnace integrated with thermocouple to control the temperature in and around required temperature of $300^{\circ} \mathrm{C}$. Sintered work piece shown in figure 1 is then hot extruded in a vertical die in 100 ton Press at a temperature of $250^{\circ} \mathrm{C}$ heated using an oil fired furnace. Then, the extruded billet shown in figure 2 was machined and finished to a required shape and size.

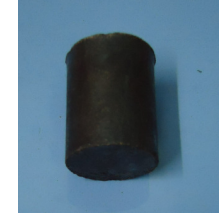

Figure 1: Sintered specimen

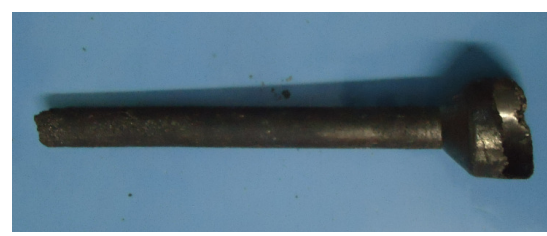

Figure 2: Extruded specimen

\subsection{Experimental Design}

Taguchi method which is a powerful tool in parameter design was used for conducting the experiments. It provides a simple, efficient and systematic approach to optimize the design for performance, quality and cost. This methodology is valuable when the design parameters are qualitative and discrete [14]. In this present work, L9 $\left(3^{4}\right)$ orthogonal array was used to design the experiments and each experiments were conducted for 3 trails. Wear test was carried out for 3 parameters such as volume fraction of graphite reinforced, normal load, disc speed at three different levels. Table 1 list the parameters at three different levels which were used to control and execute the test.

Table 1: Parameters used to control the experiment

\begin{tabular}{|c|c|c|c|}
\hline Level & $\begin{array}{c}\text { Volume } \\
\text { Fraction, } \\
\%\end{array}$ & $\begin{array}{c}\text { Disc } \\
\text { Speed, } \\
\mathbf{m} / \mathbf{s}\end{array}$ & $\begin{array}{c}\text { Normal } \\
\text { Load, } \mathbf{N}\end{array}$ \\
\hline 1 & 5 & 0.8 & 10 \\
\hline 2 & 10 & 1.6 & 15 \\
\hline 3 & 15 & 2.4 & 20 \\
\hline
\end{tabular}

Table 2 : Hardness (HRB) of the composite material

\begin{tabular}{|c|c|c|c|c|c|c|c|}
\hline Trail & 1 & 2 & 3 & 4 & 5 & 6 & Avg. \\
\hline 0\% Grp & 35 & 47 & 21 & 23 & 19 & 25 & 28.33 \\
\hline 5\% Grp & 54 & 24 & 57 & 29 & 26 & 33 & 37.33 \\
\hline 10\% Grp & 81 & 87 & 54 & 84 & 55 & 78 & 73.167 \\
\hline 15\% Grp & 60 & 75 & 74 & 62 & 79 & 71 & 68.5 \\
\hline
\end{tabular}


Table 3: Density of the $\mathrm{Mg} / \mathrm{Grp}$ Composites

\begin{tabular}{|c|c|c|c|c|}
\hline $\begin{array}{c}\text { Volume } \\
\text { Fraction, } \\
\text { \% }\end{array}$ & 0 & 5 & 10 & 15 \\
\hline $\begin{array}{c}\text { Density, } \\
\text { g/cm }\end{array}$ & 1.6532 & 1.5798 & 1.7224 & 1.6903 \\
\hline $\begin{array}{c}\text { \% } \\
\text { density }\end{array}$ & 99.08 & 99.7395 & 98.9648 & 96.68 \\
\hline
\end{tabular}

\subsection{Experimental Procedure}

Density of the composite with varying composition was estimated with the help of Archimedes principle. Specimens prepared in equal size were weighed in electronic weighing machine and then immersed in water with the help of a balance and a beaker. Electronic weighing machine which was initially at one buoyancy shows the density of specimen. As per ASTM standard of E 18-08b, hardness of the composite was found using Rockwell Hardness Tester in B scale along the direction of extrusion. Ball indenter of size $\emptyset(1 / 16) "$ was used as indenter and v-block was used as a mounting device. Table 2 lists the value of density and \%density of composites and Table 3 lists hardness of the composites.

Wear test was carried out in a pin-on-disc configuration in a wear test machine as per the ASTM standard of G 99-05. Composite samples which were in pin form and a standard material was used as a disc. In this system, the sample was clamped in a holder and held vertically against the rotating disc made of $\mathrm{C} 45$ tool steel. The disc used was ensured to have same surface roughness before each experiments and acetone was used to clean the disc from impurities. The whole experiments were conducted under dry friction condition at the atmospheric temperature as per the design. Computer interfaced microcontroller was used to control parameters of the experiment. Software installed in computer displays measured values of coefficient of friction and wear loss.

\section{GREY RELATIONAL ANALYSIS}

The grey relational analysis (GRA) associated with the Taguchi method represents a new approach to optimization. The grey theory is based on the random uncertainty of small samples which developed into an evaluation technique to solve certain problems of systems that are complex and having incomplete information. A system for which the relevant information is completely known is a 'white' system, while a system for which the relevant information is completely unknown is a 'black' system. Any system between these limits is a 'grey' system having poor and limited information. Grey relational analysis (GRA), which is a normalisation technique, is extended to solve the complicated multi-performance characteristics.

\subsection{Analysis Approach}

The grey relational analysis is used in conjunction with orthogonal array to draw inferences about the effect of the factors and their interactions on multiple responses. It is an effective tool when compared to earlier approaches. In this, Experiment is conducted for at least two replications with respect to each trail in the orthogonal array and the values of the response variables were estimated, let the number of replications be $r$. 


\subsection{Methodology}

In this PHASE of the analysis, the normalized values of the response are computed using the equations. The maximum of the normalized values, difference between each normalized value and the reference value $\mathrm{R}$, regardless of the response variables, trails and replications are estimated.

For 'higher-the-better' performance variable, the formula for the response variable $\mathrm{I}$ is given below for each replication $\mathrm{k}=1,2,3, \mathrm{r}$.

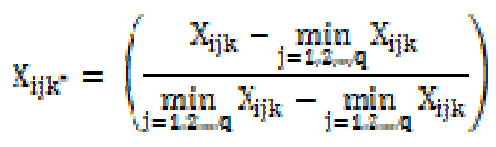

Where, $\mathrm{X}_{\mathrm{ijk}}{ }^{*}$ is the normalized value after grey relational generation of the higher is better type of response variable for the $\mathrm{k}^{\text {th }}$ replication of the $\mathrm{j}^{\text {th }}$ trail, $\mathrm{j}=1,2,3, \ldots, \mathrm{q}$ and $\mathrm{k}=1,2, \ldots, \mathrm{r}, \mathrm{q}$ is the number of trails, and $r$ is the number of replications.

For 'lower-the-better' performance variable, the formula for the response variable I is given below for each replication $\mathrm{k}=1,2,3$, $\mathrm{r}$.

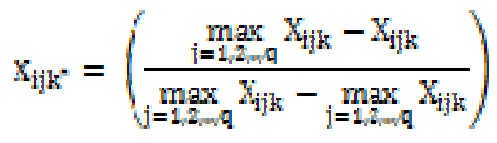

Where, $\mathbf{X}_{\mathbf{i j k}}{ }^{*}$ is the normalized value after grey relational generation of the lower-the-better type of response variable for the $\mathrm{k}^{\text {th }}$ replication of the $\mathrm{j}^{\text {th }}$ trail, $\mathrm{j}=1,2,3, . ., \mathrm{q}$ and $\mathrm{k}=1,2, \ldots, \mathrm{r}, \mathrm{q}$ is the number of trails, and $r$ is the number of replications.

The grey relational coefficient $\left(\xi_{\mathrm{ijk}}\right)$ for each of the normalized values $\left(\mathrm{X}_{\mathrm{ijk}} *\right)$ in the problem is computed using the equation, were $\xi_{\mathrm{ijk}}$ is the grey relational coefficient for the $\mathrm{i}^{\text {th }}$ response variable, jth trail and kth replication and $\zeta$ is distinguishing coefficient in the range 0 to 1 . Table 4 list the outcome of grey relational analysis.

$$
\xi_{i j k}=\frac{\operatorname{Min} \Lambda_{i j k}+\operatorname{Mrx} \Lambda_{i j k}}{\Delta_{i j k}+7 \operatorname{Max} \Delta_{i j k}}
$$

Table 4: Grey Relational Co-efficient and Grade for each run

\begin{tabular}{|c|c|c|c|c|c|}
\hline \multirow{2}{*}{ RUNS } & \multicolumn{2}{|c|}{$\begin{array}{c}\text { Normalised } \\
\text { Response }\end{array}$} & \multicolumn{2}{c|}{$\begin{array}{c}\text { Grey Relational } \\
\text { Coefficient }\end{array}$} & \multirow{2}{*}{ GRG } \\
\cline { 2 - 5 } & $\begin{array}{c}\text { Co-eff. } \\
\text { Friction }\end{array}$ & $\begin{array}{c}\text { Wear } \\
\text { Rate }\end{array}$ & $\begin{array}{c}\text { Co-eff. } \\
\text { Friction }\end{array}$ & $\begin{array}{c}\text { Wear } \\
\text { Rate }\end{array}$ & \\
\hline 1 & 0 & 0.8231 & 1 & 0.3779 & 0.6889 \\
\hline 2 & 1 & 0.7458 & 0.3333 & 0.4013 & 0.3673 \\
\hline 3 & 0.9075 & 1 & 0.3552 & 0.3333 & 0.3442 \\
\hline 4 & 0.8043 & 0.8525 & 0.3833 & 0.3696 & 0.3764 \\
\hline 5 & 0.5738 & 0.4479 & 0.4656 & 0.5275 & 0.4965 \\
\hline 6 & 0.9181 & 0.5543 & 0.3526 & 0.4742 & 0.4134 \\
\hline 7 & 0.8721 & 0.6199 & 0.3644 & 0.4465 & 0.4054 \\
\hline 8 & 0.9049 & 0.5497 & 0.3558 & 0.4567 & 0.4062 \\
\hline 9 & 0.9358 & 0 & 0.3482 & 1 & 0.6747 \\
\hline
\end{tabular}


The average of grey relational grade for each of the factors which is computed by writing the grey relational grades against the trails of the orthogonal array is listed in table 5. Grey relational grade or code is computed from formula

$$
\frac{\sum_{i=1}^{D} E_{k=1} k_{i j k}}{F^{r}} .
$$

The optimal level for each factor is identified based on higher is better characteristic. After performing Grey Relational Analysis, its factors are used to perform Analysis of variance in order to identify significance of factors in design and contribution of each factor to the Grey Relational Grade.

Table 5: Average Grey Relational Grade for Each Factor

\begin{tabular}{|c|c|c|c|}
\hline LEVELS & $\begin{array}{c}\text { Volume } \\
\text { Fraction }\end{array}$ & $\begin{array}{c}\text { Normal } \\
\text { Load }\end{array}$ & Disc Speed \\
\hline 1 & 0.5142 & 0.4774 & 0.5851 \\
\hline 2 & 0.4968 & 0.5431 & 0.4832 \\
\hline 3 & 0.486 & 0.4766 & 0.4288 \\
\hline
\end{tabular}

\section{RESULTS AND DISCUSSION}

\subsection{Analysis of Variance for Grey Relational Grade}

By using GRA multi objective problem is converted into a single objective which is given by Grey Relational Grade. ANOVA is performed on the response GRG against each factor in order to reveal the significance of influence of factors. The response table of Taguchi method is employed here to obtain ANOVA table which is shown in table 6.

Contribution of each factor is also revealed in the table and surface graph is plotted for GRG which shown in fig 3-5. The results of ANOVA indicates that Grey Relational Grade depends mostly on Load applied and almost nil on speed of the disc, even volume fraction have

Table 6: ANOVA Table for Grey Relational Grade

\begin{tabular}{|c|c|c|c|c|c|c|}
\hline Factor & $\begin{array}{c}\text { Sum of } \\
\text { Squares }\end{array}$ & $\begin{array}{c}\text { Degree of } \\
\text { Freedom }\end{array}$ & $\begin{array}{c}\text { Mean } \\
\text { Square }\end{array}$ & $\begin{array}{c}\mathbf{F} \\
\text { Value }\end{array}$ & $\begin{array}{c}\text { Prob. } \\
\mathbf{>} \text { F }\end{array}$ & $\begin{array}{c}\text { Contribution } \\
\mathbf{\%}\end{array}$ \\
\hline A-Vf & $\begin{array}{c}3.936 \mathrm{E}- \\
003\end{array}$ & 1 & $\begin{array}{c}3.936 \mathrm{E}- \\
003\end{array}$ & 13.05 & 0.0688 & 8.0326 \\
\hline B-LOAD & 0.018 & 1 & 0.018 & 60.77 & 0.0161 & 36.734 \\
\hline C-SPEED & $\begin{array}{c}2.246 \mathrm{E}- \\
005\end{array}$ & 1 & $\begin{array}{c}2.246 \mathrm{E}- \\
005\end{array}$ & 0.074 & 0.8105 & 0.0458 \\
\hline $\mathrm{AB}$ & $\begin{array}{c}6.192 \mathrm{E}- \\
003\end{array}$ & 1 & $\begin{array}{c}6.192 \mathrm{E}- \\
003\end{array}$ & 20.53 & 0.0454 & 12.636 \\
\hline $\mathrm{BC}$ & $\begin{array}{c}2.558 \mathrm{E}- \\
003\end{array}$ & 1 & $\begin{array}{c}2.558 \mathrm{E}- \\
003\end{array}$ & 8.48 & 0.1005 & 5.2204 \\
\hline B 2 & 0.017 & 1 & 0.017 & 56.70 & 0.0172 & 34.69 \\
\hline Residual & $\begin{array}{c}6.032 \mathrm{E}- \\
004\end{array}$ & 2 & $\begin{array}{c}3.016 \mathrm{E}- \\
004\end{array}$ & & & \\
\hline Cor Total & 0.049 & 8 & & & & \\
\hline
\end{tabular}


remarkable contribution on GRG. Even with the interaction effect disc speed loses its identity, interaction of volume fraction and load shows greater contribution than volume fraction on its own.

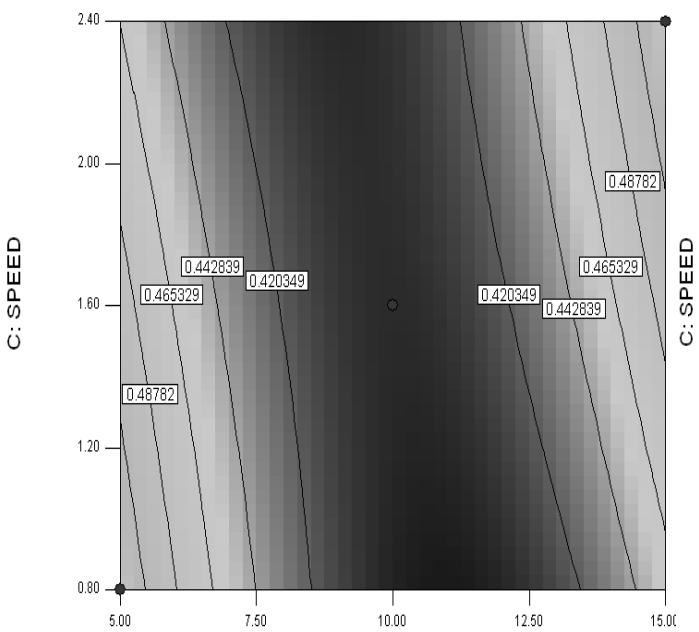

B: LOAD

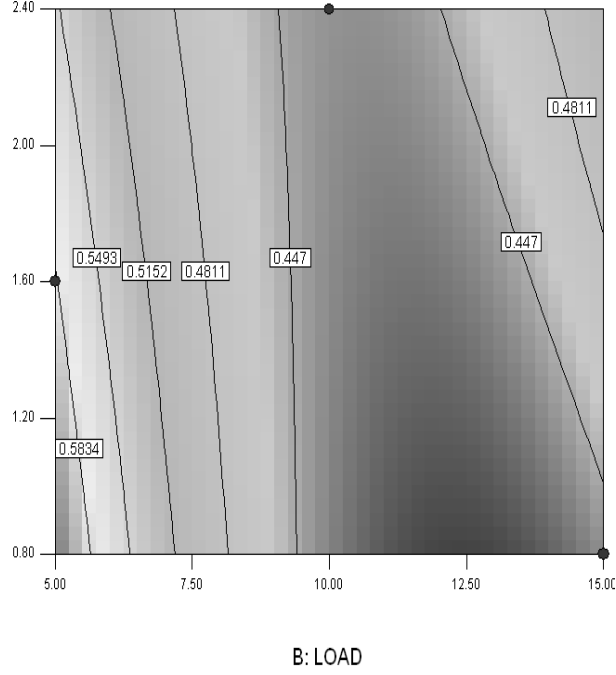

Figure 4: GRG for $10 \% \mathrm{Gr} / \mathrm{Mg}$ composite

Figure 3: GRG for 5\% Gr/Mg composite.

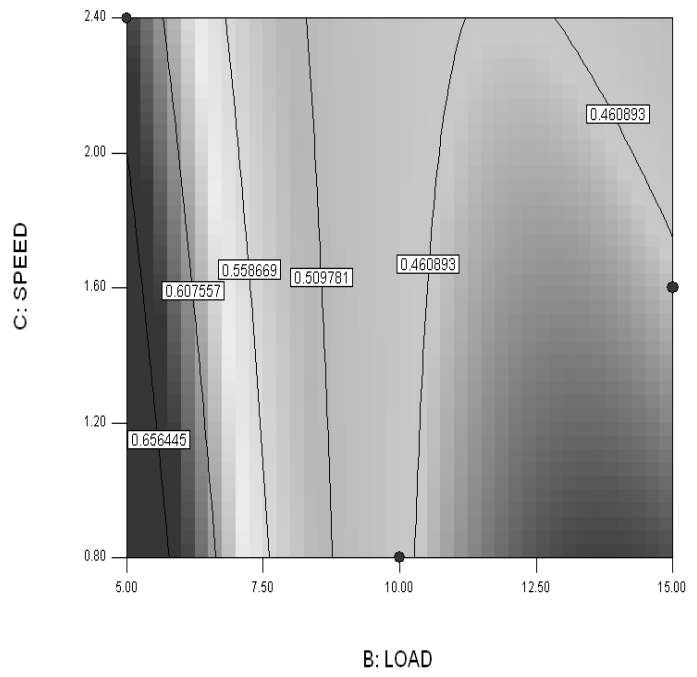

Figure 5: GRG for $15 \%$ Gr reinforced Mg composite

\section{2. $\quad$ Effects of Volume Fraction on Grey Relational Grade}

There is considerable variation in grey relational grade with volume fraction. At 5\% volume fraction, lower load and lower speed show best grade. At the same time higher speed and higher load show good values of grades. Increase in volume fraction increases value of grey relational code at lower load levels for all speed levels. But at high loads levels trend of increase in grey relational grade with speed decreases as volume fraction increases. In all over the volume fraction increases then grey relational grade increases. Where as in Composite materials resistance to plastic deformation can be increased by impeding the movement of dislocation on slip planes, for increasing yield strength different obstacles can be thrown in the way of 
dislocation. Due to this reasons grey relational grade increase with volume fraction as movement of dislocation obstructed. For the same reason hardness and density of composite increases with the increase in Graphite composition showing maximum to be at $10 \%$ Grp composition, where as in wear loss at 5\% Grp values on all the trails are closer to the minimum value than other compositions.

\subsection{Effect of Load on Grey Relational Grade}

Changes in grey relational grade largely depend up on load variation. Smaller the load then value of grey relational grade is higher and considerably changes with increase in load. There is a saturation point at which decrease in grade stops starts increasing from it. Also this saturation point moves towards larger load with increase in volume fraction of graphite. In composite materials reinforcement carry greater part of load than their volume fraction. Smearing of filler and matrix material depends upon the brittleness and identity of the materials. Dependency of grey relational grade largely on load indicates the soft nature of the reinforcement material and density of magnesium which is low.

\subsection{Effect of Speed on Grey Relational Grade}

There is not much change in grey relational grade with change in speed of disc. However it contributes to a certain level due to thermal softening of material, which increases with increase in speed. Increasing the speed increases grey relational grade when the load is at its higher level. Wear loss of material is directly proportional to sliding distance, but hardness or coefficient of friction does not depend upon the disc speed. Therefore Grey Relational Grade is not much depended on disc speed.

\section{CONCLUSIONS}

1. The recommended levels of parameters for an optimum grey relational grade is $5 \%$ volume fraction with grey relational grade of 0.5142 and $10 \mathrm{~N}$ load with grey relational grade of 0.5431 and $0.8 \mathrm{~m} / \mathrm{s}$ of grey relational grade of 0.5851 which is obtained by grey relational analysis.

2. ANOVA for grey relational grade states that contribution on grey relational grade by Normal load is about $70 \%$ and by volume fraction is just less than $10 \%$ but contribution of disc speed is lesser than contributions of interaction effects.

3. Generally increase in volume fraction of Graphite there shows good property of the composite materials against wear.

4. The experimental results for optimal settings show that there is a considerable improvement in wear characteristics of material. This technique is more convenient and economical to predict the effect of different influential combinations of the parameters within the levels studied.

\section{ACKNOWLEDGEMENT}

The authors would like to express their sincere gratitude to Prof. R. Sethuraman, Vice chancellor, SASTRA University, Thanjavur, India and Shanmugha Precision Forging, Thanjavur, India for supporting this work.

The authors would like to express their sincere gratitude to Dr. T.Rajmohan, Professor, SCSVMV University, Kanchipuram, India for sharing his knowledge. 


\section{REFERENCES}

[1] J.W. Kaczmar, K. Pietrzak, W. Wosinâski (2000) "The production and application of metal matrix composite materials", journal of materials processing technology 106.

[2] Greco, K. Mistry, V. Sista, O. Eryilmaz, A. Erdemir, (2011) "Friction and wear behaviour of boron based surface treatment and nano-particle lubricant additives for wind turbine gearbox applications", wear 271.

[3] Qi Qing-Ju, (2006) "Evaluation of sliding wear behaviour of graphite particle-containing magnesium alloy composites", Trans. Nonferrous met. Soc. China 16.

[4] Zhang Mei-Juan, Cao Zhan-Yi, Yang Xiao-Hong, Liu Yong-Bing, (2010) "Microstructures and wear properties of graphite and al2o3 reinforced az91d-cex composites", Trans. Nonferrous met. Soc. China 20.

[5] T. Miyajima, Y. Iwai, (2003) "Effects of reinforcements on sliding wear behaviour of aluminium matrix composites", wear 255.

[6] C.Y.H. Lim, D.K. Leo, J.J.S. Ang, M. Gupta, (2005) "Wear of magnesium composites reinforced with nano-sized alumina particulates", wear 259.

[7] S.C. Sharma, B. Anand, M. Krishna, (2000) "Evaluation of sliding wear behaviour of feldspar particle-reinforced magnesium alloy composites", wear 241.

[8] Ege Anil Diler And Rasim Ipek, "Main and interaction effects of matrix particle size, reinforcement particle size and volume fraction on wear characteristics of al-sic composites using central composite design", jcomb 2236.

[9] S. Kumar, V.Balasubramanian, (2010) "Effect of reinforcement size and volume fraction on the abrasive wear behaviour of aa7075al/sic p/m composites-a statistical analysis", Tribology international 43.

[10] Feng Wu, Jing Zhu, K. Ibe \& T. Oikawa, (1998) "Analysis of the interface in graphite/magnesium composites at the nanometre scale", Composites science and technology 58.

[11] Y.W. Wu, K.Wu, K.K. Deng, K.B. Nie, X.J. Wang, X.S. Hu, M.Y. Zheng, (2010) "Damping capacities and tensile properties of magnesium matrix composites reinforced by graphite particles", Materials science and engineering a 527.

[12] Y.W. Wu*, K. Wu, K.K. Deng, K.B. Nie, X.J. Wang, M.Y. Zheng, X.S. Hu, (2010) "Damping capacities and microstructures of magnesium matrix composites reinforced by graphite particles", materials and design 31 .

[13] J. Corrochano, M. Lieblich *, J. Ibáñez, (2009) "On the role of matrix grain size and particulate reinforcement on the hardness of powder metallurgy al-mg-si/mosi2 composites", Composites science and technology 69.

[14] T. Rajmohan, K. Palanikumar, M. Kathirvel, (2012) "Optimization of machining parameters indrilling hybrid aluminium metal matrix composites”, Trans. Nonferrous Met. Soc. China 22.

[15] Ulas Caydas, Ahmet Hascalik, (2008) "Use of the grey relational analysis to determine optimum laser cutting parameters with multi-performance characteristics", Optics \& Laser Technology 40.

[16] P. Narender Singh , K. Raghukandan , B.C. Pai , (2004) "Optimization by Grey relational analysis of EDM parameters on machining $\mathrm{Al}-10 \% \mathrm{SiCP}$ composites", Journal of Materials Processing Technology 155-156. 